\title{
Single nucleotide polymorphisms as the new predictors of therapy decisions in gastroesophageal junction and gastric adenocarcinoma?
}

\author{
Lukas Perkhofer, Alexander Hann \\ Department of Internal Medicine I, University of Ulm, Ulm, Germany \\ Correspondence to: Dr. med. Alexander Hann. Department of Internal Medicine I, University of Ulm, Albert-Einstein-Allee 23, 89081 Ulm, Germany. \\ Email: Alexander.Hann@uni-ulm.de. \\ Comment on: Schulz C, Zhang W, Lenz HJ, et al. Germline polymorphisms (SNPs) to predict toxicity and efficacy in FLOT-treated patients with \\ locally advanced gastroesophageal junction or gastric adenocarcinoma-data from the NeoFLOT study. Transl Cancer Res 2018;7:1393-405.
}

Submitted Apr 25, 2019. Accepted for publication May 10, 2019.

doi: $10.21037 /$ tcr.2019.05.10

View this article at: http://dx.doi.org/10.21037/tcr.2019.05.10

Western populations show a remarkable switch in gastroesophageal cancer phenotype with predominance for adenocarcinomas nowadays (1). This contrasts the rest of the world and is mainly caused by lifestyle factors (2). Thereby, obesity and gastroesophageal reflux with Barret's esophagus are the suspected correlates $(3,4)$. Primary diagnosis of gastroesophageal junction (GEC)/ gastric cancer (GC) with potentially curatively resectable disease stage is not uncommon (5). Though submucosal infiltration is frequently found with and increased risk of prognostic relevant lymph-node metastases. In line the Magic trial (6) first implemented the concept of perioperative chemotherapy to be superior compared to up front surgery. Therefore, Cunningham et al. made use of the palliative established ECF-regimen (epirubicin, cisplatin, 5-fluorouracil). Subsequently the significance of perioperative chemotherapy was underpinned by the ACCORD 07 trial with 5-fluorouracil/cisplatin (7). Moreover, the FLOT (docetaxel, oxaliplatin, 5-fluorouracil/ leucovorin) protocol showed promising results in palliative care $(8,9)$ and therefore was transferred to the perioperative setting as well. The recently published FLOT4 study demonstrated superiority of FLOT compared to the ECF/ ECX (capecitabine instead of 5-FU) regimen, regarding overall survival (OS) (10). Summarized perioperative chemotherapy established as standard of care in UICC II and III esophageal cancers [ $\geq \mathrm{cT} 2$ tumors and/or suspect local lymph node status $(\mathrm{N})]$ and entered guideline recommendations $(11,12)$. However, irrespective of the regimen used they all reflect classical chemotherapies and thereby being far from personalized and lacking evidence of individual efficacy and toxicity.

Consequently Schulz et al. recently published an interesting novel approach as a spin-off of the NeoFLOT trial. The NeoFLOT trial itself addressed the use of prolonged neoadjuvant chemotherapy (6 cycles of FLOT) in patients with T3 and T4 GEC/GC. The rationale of the trial is the high number of patients that do not receive adjuvant chemotherapy to different reasons (10). The NeoFLOT trial proved effectivity and tolerability of prolonged neoadjuvant FLOT therapy, exposing intestinal type tumors as a subgroup of very good responders. Ideally the trial came along with a translational side project that was now addressed focusing on the need for predictive markers that on the one hand select for therapy responders. On the other hand, select those patients that suffer relevant side effects from therapy. As toxicity is a major hurdle that at worst can postpone resection or negatively influence postoperative outcome caused by e.g., excessive weight loss or remaining side effects. Thereby, Schulz et al. took advantage of previously published data on single nucleotide polymorphisms (SNPs) for genes related to pyrimidine and methionine biosynthesis, DNA repair and thymidylate synthase. SNPs represent sequence variations caused by stable substitution of a single base in the DNA. This common phenomenon drives genetic variation among people but mostly not affect health. Nevertheless, SNPs have the potential to act as biological markers and can 
affect gene functions, outlined in various publications in GEC/GC (13-17). Within this study DNA was extracted from formalin embedded tumor specimen followed by PCR-based analysis of the candidate SNPs. Results were correlated to the prospectively obtained data and showed significant association with toxicity and less for survival and tumor response.

Predominantly hematotoxicity occurred and was related to SNPs in the nucleotide excision repair proteins ERCC2 (rs1799793 and rs13181) and ERCC1 (rs11615). Interestingly thereby ERCC2 rs1799793 SNPs had a different impact: (I) AA drives thrombocytopenia, (II) $\mathrm{A} / \mathrm{G}$ and $\mathrm{G} / \mathrm{G}$ neutropenia. In line, a $\mathrm{G} / \mathrm{G}$ polymorphism in the methionine synthase (MTR) Rs1805087 was significantly associated with $\geq$ grade 2 anemia. Polymorphisms in the MTR (rs1805087) were strongly and in ERCC2 (rs1799793 and rs13181) to a lesser extend associated with diarrhea. Selective SNPs related to polyneuropathy development in view of the combined therapy with oxaliplatin and docetaxel in the FLOT protocol were not found. OPRT rs1801019 G/A, an enzyme involved in the pyrimidine biosynthesis, showed best association to overall response rate with increased but statically non-significant prolonged PFS and OS.

Interestingly none of the SNPs were associated with significant survival advantages but much more none of them predicted worse prognosis. Limitations of the trial were given to the small sample size and missing controls. However, data shown was largely in concordance with published findings and thereby strengthens the value and robustness of the approach. The data presented should be the basis for further prospective trials with respect to toxicity stratification that allow timely dose adaption. Therefore, GEC and GC offer the ideal prerequisites as normally being easily and repetitively accessible.

Summarized Schulz et al. carried out an approach that could be easy to implement in routine diagnostic with a pre-defined primer set and may help to improve therapy outcome.

\section{Acknowledgments}

Funding: None.

\section{Footnote}

Provenance and Peer Review: This article was commissioned by the editorial office, Translational Cancer Research. The article did not undergo external peer review.

Conflicts of Interest: Both authors have completed the ICMJE uniform disclosure form (available at http://dx.doi. org/10.21037/tcr.2019.05.10). The authors have no conflicts of interest to declare.

Etbical Statement: The authors are accountable for all aspects of the work in ensuring that questions related to the accuracy or integrity of any part of the work are appropriately investigated and resolved.

Open Access Statement: This is an Open Access article distributed in accordance with the Creative Commons Attribution-NonCommercial-NoDerivs 4.0 International License (CC BY-NC-ND 4.0), which permits the noncommercial replication and distribution of the article with the strict proviso that no changes or edits are made and the original work is properly cited (including links to both the formal publication through the relevant DOI and the license). See: https://creativecommons.org/licenses/by-nc-nd/4.0/.

\section{References}

1. Arnold M, Soerjomataram I, Ferlay J, et al. Global incidence of oesophageal cancer by histological subtype in 2012. Gut 2015;64:381-7.

2. Bray F, Ferlay J, Soerjomataram I, et al. Global cancer statistics 2018: GLOBOCAN estimates of incidence and mortality worldwide for 36 cancers in 185 countries. CA Cancer J Clin 2018;68:394-424.

3. Lagergren J, Smyth E, Cunningham D, et al. Oesophageal cancer. Lancet 2017;390:2383-96.

4. Dong J, Buas MF, Gharahkhani P, et al. Determining Risk of Barrett's Esophagus and Esophageal Adenocarcinoma Based on Epidemiologic Factors and Genetic Variants. Gastroenterology 2018;154:1273-81.e3.

5. Zhang Y. Epidemiology of esophageal cancer. World J Gastroenterol 2013;19:5598-606.

6. Cunningham D, Allum WH, Stenning SP, et al. Perioperative chemotherapy versus surgery alone for resectable gastroesophageal cancer. $\mathrm{N}$ Engl J Med 2006;355:11-20.

7. Boige V, Pignon J, Saint-Aubert B, et al. Final results of a randomized trial comparing preoperative 5 -fluorouracil $(\mathrm{F}) /$ cisplatin $(\mathrm{P})$ to surgery alone in adenocarcinoma of stomach and lower esophagus (ASLE): FNLCC ACCORD07-FFCD 9703 trial. J Clin Oncol 
2007;25:4510.

8. Al-Batran SE, Hartmann JT, Hofheinz R, et al. Biweekly fluorouracil, leucovorin, oxaliplatin, and docetaxel (FLOT) for patients with metastatic adenocarcinoma of the stomach or esophagogastric junction: a phase II trial of the Arbeitsgemeinschaft Internistische Onkologie. Ann Oncol 2008;19:1882-7.

9. Homann N, Pauligk C, Luley K, et al. Pathological complete remission in patients with oesophagogastric cancer receiving preoperative 5-fluorouracil, oxaliplatin and docetaxel. Int J Cancer 2012;130:1706-13.

10. Al-Batran SE, Homann N, Pauligk C, et al. Perioperative chemotherapy with fluorouracil plus leucovorin, oxaliplatin, and docetaxel versus fluorouracil or capecitabine plus cisplatin and epirubicin for locally advanced, resectable gastric or gastro-oesophageal junction adenocarcinoma (FLOT4): a randomised, phase 2/3 trial. Lancet 2019;393:1948-57.

11. Porschen R, Fischbach W, Gockel I, et al. Z Gastroenterol 2019;57:336-418.

12. Lordick F, Mariette C, Haustermans K, et al. Oesophageal cancer: ESMO Clinical Practice Guidelines for diagnosis, treatment and follow-up†. Ann Oncol 2016;27:v50-7.

13. Jing JJ, Lu YZ, Sun LP, et al. Epistatic SNP interaction of ERCC6 with ERCC8 and their joint protein expression contribute to gastric cancer/atrophic gastritis risk. Oncotarget 2017;8:43140-52.

14. Lv Z, Sun L, Xu Q, et al. SNP interactions of PGC with its neighbor lncRNAs enhance the susceptibility to gastric cancer/atrophic gastritis and influence the expression of involved molecules. Cancer Med 2018;7:5252-71.

15. Romero S, Musleh M, Bustamante M, et al. Polymorphisms in TWIST1 and ZEB1 Are Associated with Prognosis of Gastric Cancer Patients. Anticancer Res 2018;38:3871-7.

16. Gharahkhani P, Fitzgerald RC, Vaughan TL, et al. Genome-wide association studies in oesophageal adenocarcinoma and Barrett's oesophagus: a large-scale meta-analysis. Lancet Oncol 2016;17:1363-73.

17. Ghadban T, Schmidt-Yang M, Uzunoglu FG, et al. An $\mathrm{A} / \mathrm{C}$ germline single-nucleotide polymorphism in the TNFAIP3 gene is associated with advanced disease stage and survival in only surgically treated esophageal cancer. J Hum Genet 2014;59:661-6.
Cite this article as: Perkhofer L, Hann A. Single nucleotide polymorphisms as the new predictors of therapy decisions in gastroesophageal junction and gastric adenocarcinoma? Transl Cancer Res 2019;8(5):1656-1658. doi: 10.21037/tcr.2019.05.10 